\title{
CONGENITAL WEB FORMATION
}

\section{Shun-Shin, Port Louis, Mauritius}

On the small island of Rodriguez, measuring about six miles by four miles and lying 300 miles east of Mauritius, of which it is a dependency, there exists in three generations of one family the abnormal condition of webbing of the elbow. As will be seen from the family tree (Fig. 1) the head of the family, Eudoxe (Fig. 2), had the condition on one side only. As far as he was aware, none of his forebears had shown this congenital defect, which had also spared his siblings. Of his twelve children, two sons and two daughters inherited the condition, the involvement being in every instance bilateral. The sons, Wilford (Fig. 3) and Lewis, were both seen but neither of the daughters would consent to examination. There seemed, however, from Eudoxe's firm assurance, little doubt that they suffered from the same deformity. Wilford was unmarried but Lewis was the father of seven children. His first born, a girl, was alleged to show the abnormality in one elbow in a very mild degree and his fifth child, Job, a young boy of ten, had the elbow on each side affected (Fig. 4). It was only when he was admitted to hospital for tonsillectomy that this familial congenital deformity was detected. Only one of the affected daughters of the first generation had married and her two children were normal.

One of the unaffected daughters had, however, transmitted the deformity to one of her children (a female). She could not be prevailed upon to come for examination but was believed to show webbing on one side only. The remaining members of this big family group were normal.

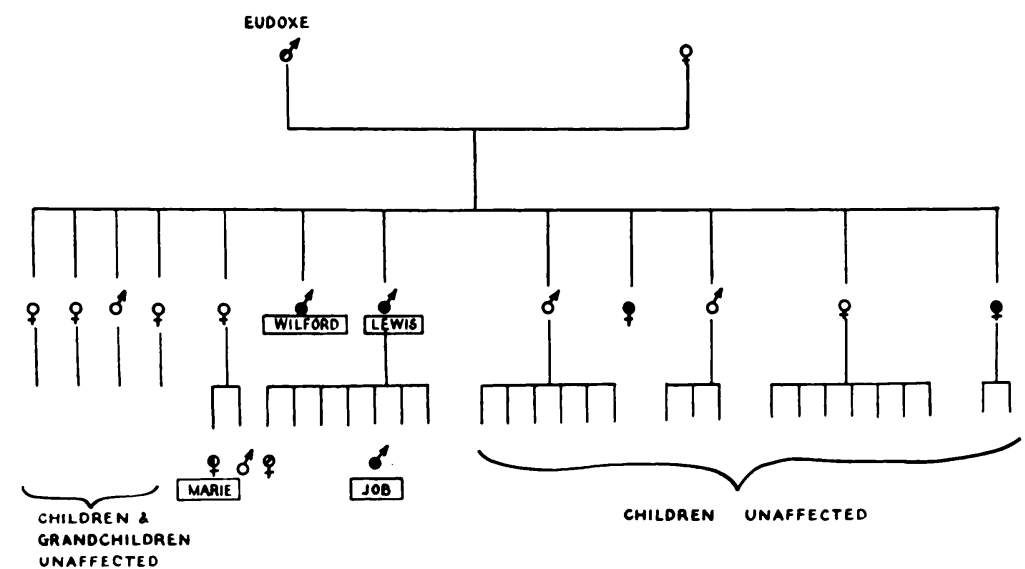

FIG. 1

Family tree to show the members of the family affected. $\bullet=$ Both elbows affected. $\quad \mathbf{O}=$ one elbow affected. $\boldsymbol{\emptyset}=$ one elbow slightly affected.

In the patients examined the deformity in every instance was the same. On clinical examination, the most striking feature was the presence of a web of skin stretching across the cubital fossa from the distal third of the arm to the proximal third of the forearm. There was no interference with full flexion of the joint but extension was limited to only $\mathbf{9 0}$ degrees. Pronation and supination were also limited, the total range of rotation being no more than 90 degrees. When the elbow was flexed against resistance, the forearm being held in the semi-prone position, the web of skin was found to contain tensely contracted muscles of the flexor group. The power of this movement was not impaired. The triceps was well developed in its distal half but its proximal half felt like a fibrous cord and appeared to be imperfectly 
developed (Fig. 3). It was possible to persuade only one of the patients, Wilford, to come the $\mathbf{3 0 0}$ miles to Mauritius for radiographic examination. The limited range of movement and the presence of the web made it difficult to get a good projection but such films as we could obtain seemed to show on each side a posterior subluxation of the head of the radius, and mal-development of the radio-ulnar joint (Figs. 5 and 6).

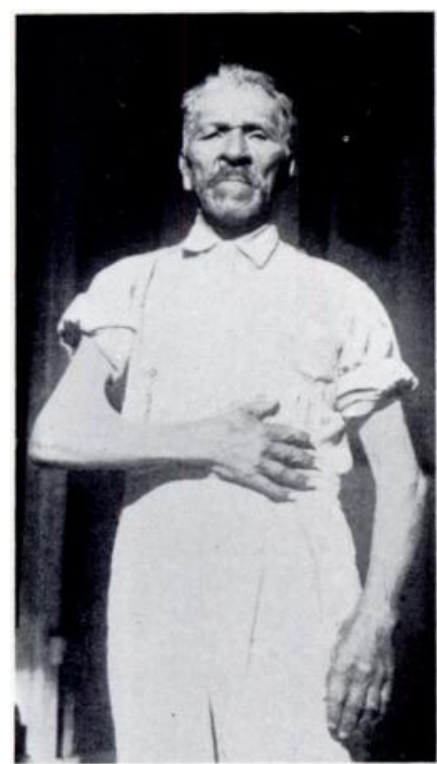

FIG. 2

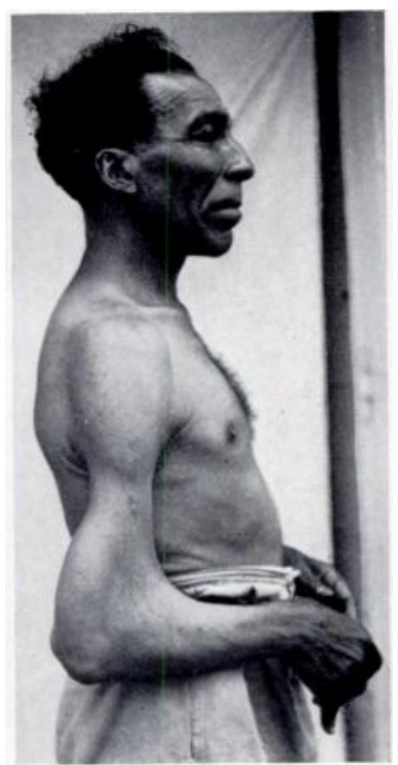

FIG. 3

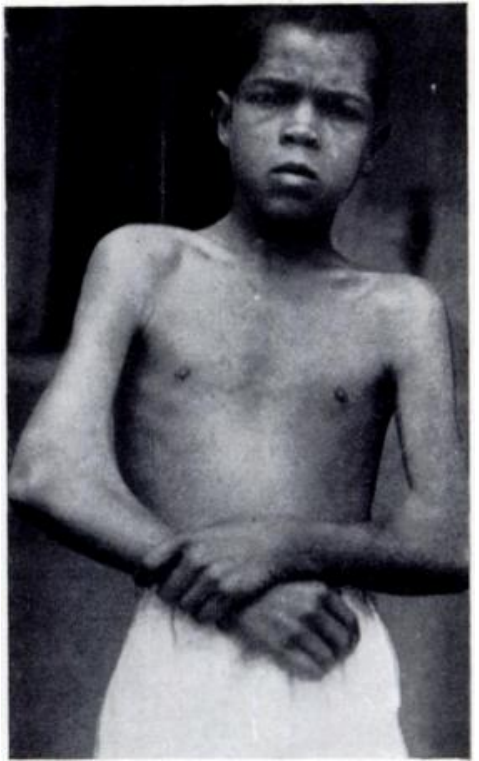

FIG. 4

Figure 2-Eudoxe, the head of the family. Figure 3-Wilford, son of Eudoxe. The left elbow was similarly affected. Lewis, another son, had the same deformity. Figure 4-Job, son of Lewis.

\section{DISCUSSION}

Although this appears to be a comparatively rare abnormality numerous examples have been reported, especially in the (ierman literature. It is but one manifestation of a congenital abnormality which may affect one or more of the following regions of the body: the neck, the axilla, the elbow, the knee and the digits. The (iermans have called it "Flughaut" (wing skin).

Kobylynski in $188: 3$ reported what he believed to be an atavistic deformity in the form of webbing of the neck in a man of twenty and Wolff in $\mathbf{1 8 8 9}$ described a girl of ten years old who had webbed skin affecting the left knee and other associated deformities including syndactyly. He was struck by the similarity between this condition and the physiological web skins (patagia) of animals.

Bruns and Kredel (1890) apparently studied the condition more closely and they were of the opinion that the deformity was due to misplaced and abnormal muscular developments bridging the flexor surfaces of joints and displacing the overlying skin in web-like formation. This was also the contention of Basch (1891), who carried out "anatomical exploration" in the neo-natal period. A further case of neck webbing was reported by Funke in 1902 but the next comprehensive reference to elbow webbing was in a paper by Ebstein in 1918, in which he reviewed the literature. He was of the opinion that the deformity was due to intra-uterine disturbances. In a further communication (1924) he described the three clinical types of webbing-pterygium colli, pterygium axillare, and pterygium digitale, cubitale and popliteum - and stated that these various anomalies might occur together or separately.

Kopits in 1937 reported three cases of webbed elbow (as well as four others in which the

vol. $36 \mathrm{~B}$, No. 2 , MAY 1954 
knee joints were affected). Extension of the elbow was in each instance limited to 90-110 degrees. Kopits believed that this loss of movement was due not to skin tension but to contracture of more deeply placed structures. In one patient radiographic examination showed dislocation of the radius. He suggested for the condition the name musculo-dysplasia congenita.

In 1938 Edwards demonstrated to the Royal Society of Medicine the case of a baby born with marked webbing in both lower limbs as well as other abnormalities. These

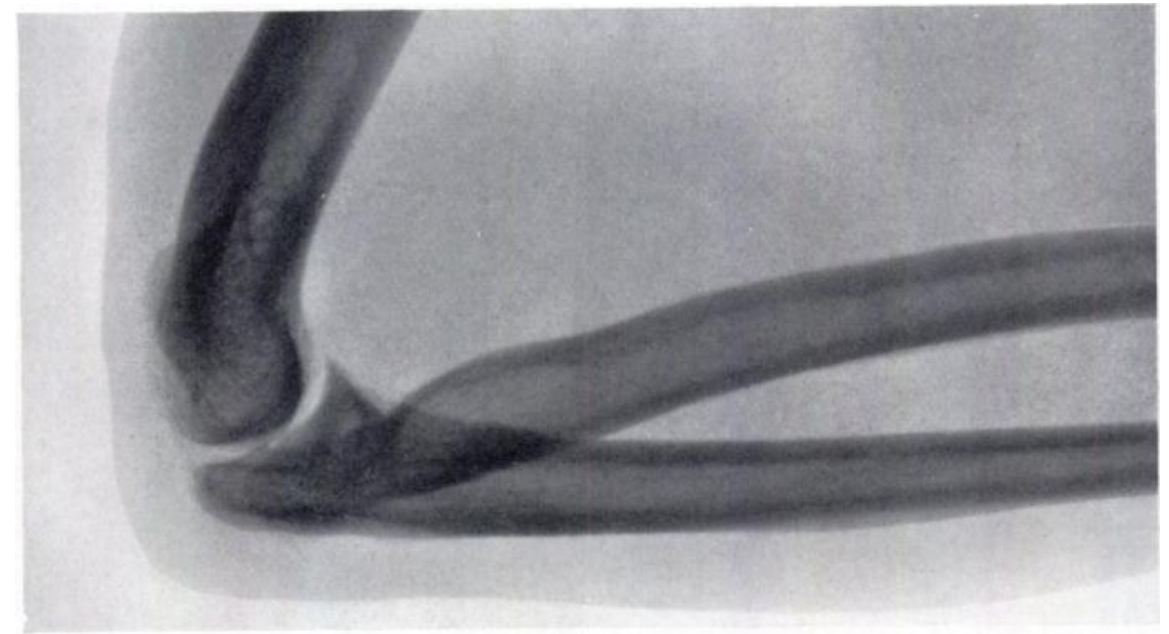

Fig. 5

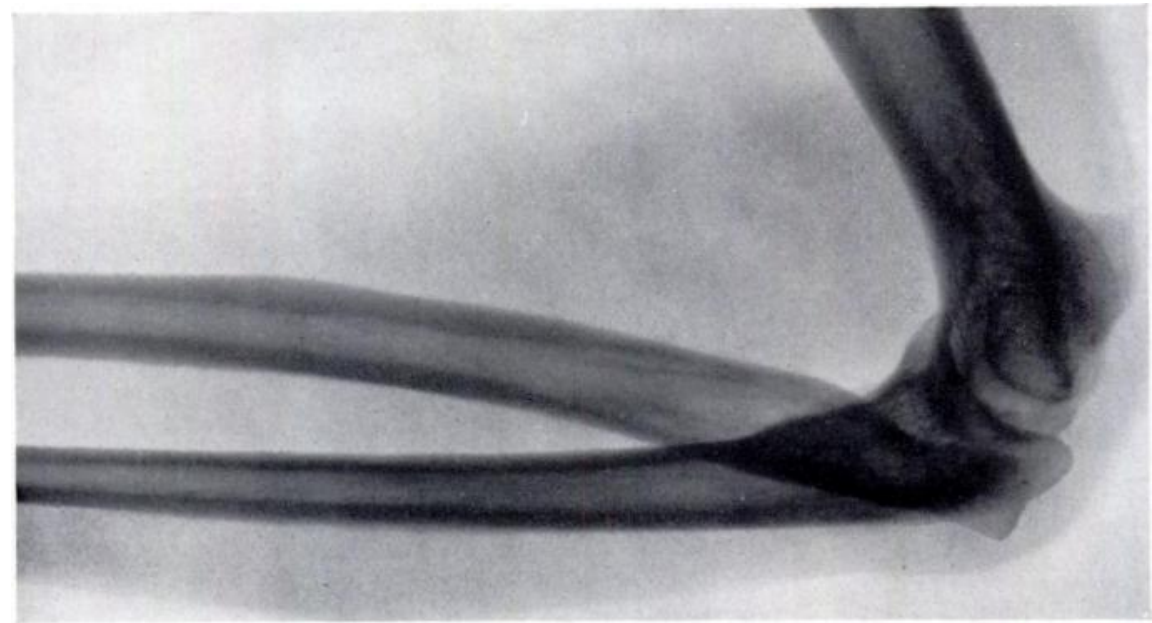

Fig. 6

Radiographs of Wilford's right and left elbows.

included marked limitation of movement at the elbows from the tenseness and contracted state of the flexor muscles: there was no webbing.

In the same year Aberle-Horstenegg described two cases of web formation between thigh and leg, in which an abnormal tendinous muscle stretched from the ischial tuberosity to the tendo calcaneus, together with other malformations such as cleft palate and cleft lip. He was of the opinion that a disturbance of development in the early foetal life was responsible for the abnormality and not a "vitium primae formationis." 
Kieser (1939) described ten members of a family of fifteen with contracture at the elbow of greater or lesser degree and frequently accompanied by atrophy of the arm and thoracic muscles. In only one case could the abnormality be definitely called webbing. The biceps and brachio-radialis and a faulty insertion of the triceps appeared to be the causes of the limitation of extension of the joint. In five cases radiographs showed bending of the radial diaphysis and subluxation of its head. Kieser believed that in addition to the web-skin there was also a simultaneous muscle dysplasia, and that the malformation, though not manifesting itself immediately after birth, was nevertheless present in the embryo. There seemed to be no question that it was a true hereditary manifestation, for which he coined the name of " myelo-osteo-musculo-dysplasia hereditaria."

Schramm (1940) described two cases of web formation. The first case was an extensive one involving the knee; the other was in a boy of thirteen with web formation in both elbows. The contracture was noticed three weeks after birth but no family history could be traced. Supination, pronation and flexion were full but extension was limited at 90 degrees. Radiographs showed dislocation of the head of the radius. Operation was undertaken but the range of extension was only bettered by 15 degrees because the blood vessels and nerves prevented further stretching. Schramm suggested the term "musculo-dysplasia-patagiata congenita" as being the most accurate.

I am indebted to the Director, Health Department, Mauritius, for permission to publish this case record. I wish to record my thanks to Mr H. J. Seddon of the Institute of Orthopaedics, and to Mr Maurice Ewing of the Postgraduate Medical School of London, for their help in its preparation. I am grateful also to the Librarian of the Institute of Orthopaedies for his help in searching the literature, and to Miss Weiss of the same institute for the German translations.

\section{REFERENCES}

Aberle-Horstenegg, W. (1938): Flughautbildung zwischen Ober- und Unterschenkel mit abnormer Muskelbildung (M. ischio-suralis). Zeitschrift für Orthopädie und ihre Grenzgebiete, 67, 21.

Basch, K. (1891): Uber sogenannte Flughautbildung beim Menschen. Zeitschrift für Heilkunde, 12, 499. (Quoted by Ebstein, 1918.)

Bruns, L., and KREDel, L. (1890): Ueber einen Fall von angeborenem Defekt mehrerer Brustmuskeln mit Flughautbildung. Fortschritte der Medicin, 8, 1. (Quoted by Edwards 1938.)

Ebstein, E. (1918): Uber das Vorkommen der Flughautbildung beim Menschen. Dermatologische Wochenschrift, 67, 607.

Fbstein, E. (1924): Ueber Einteilung und Vorkommen der Flughautbildung am menschlichen Körper. Zeitschrift für Orthopädische Chirurgie, 44, 595.

Edwards, L. M. (1938): Webbing of Lower Limbs, Associated with Congenital Bilateral Contractions of Flexcr Muscles of Elbow and Wrist. Proceedings of the Royal Society of Medicine (Clinical Section), 31, 1,053. Funke (1902): Pterygium colli. Deutsche Zeitschrift für Chirurgie, 63, 162. (Quoted by Ebstein 1918.)

Kieser, W. (1939): Die sog. Flughaut beim Menschen. Ihre Beziehung zum Status dysraphicus und ihre Erblichkeit für Menschliche Vererbungs- und Konstitutionslehre, 23, 594.

Kobylynski (1883): Uber eine flughautähnliche Ausbreitung am Halse. Archiv für Anthropologie, $14,343$. (Quoted by Ebstein 1918.)

Kopirs, E. (1937): Die als "Flughaut" bezeichneten Missbildungen und deren operative Behandlung. (Musculo-dysplasia congenita.) Archiv für Orthopädische und Unfall-chirurgie, 37, 539.

Schramm, G. (1939-40): Uber die angeborene Flughautbildung (Muskulodysplasia patagiata congenita). Zeitschrift für Orthopädie und ihre Grenzgebiete, 70, 189, 286.

WolfF, J. (1889): Uber einen Fall von angeborener Flughautbildung. Archiv für klinische Chirurgie, 38, 66. (Quoted by Ebstein 1918.) 